\title{
A CONCEPC̄̃̃ DE ENSINO PENSADA POR ROBERTO MANGE - A FORMAÇẤO DE MÃO DE OBRA SENAI: A ESCOLA DO SENAI - PR
}

\author{
THE DESIGN OF EDUCATION DESIGNED BY ROBERTO MANGE-FORMATION \\ OF LABOUR SENAI: SCHOOL OF SENAI-PR
}

Desirê Luciane Dominschek ${ }^{1}$

\begin{abstract}
RESUMO: Neste artigo volto-me ao processo de criação e desenvolvimento do Serviço Nacional de Aprendizagem Industrial (SENAI) do Paraná, destacando a forma como se pensava o ensino dos operários. A filosofia institucional de ensino pautava-se na concepção de Roberto Mange e pode ser percebida em alguns documentos, como relatórios e reportagens do Jornal "O Escudo" elaborado pelos próprios alunos do SENAI-PR. Entendo que se mesclavam uma visão taylorista com uma visão humanista nesta concepção.
\end{abstract}

Palavras-chave: SENAI. Ensino profissional. Formação para o Trabalho.

\begin{abstract}
In this article I turn to the process of creating and developing the National Service of Industrial Learning (SENAI) of Paraná, highlighting how they thought the education of workers. The institutional philosophy of education was based on the design of Roberto Mange and can be perceived in some documents, such as reports and reports from the newspaper "O Escudo" prepared by the students themselves SENAI-PR. I understand that a vision Taylor mingled with a humanistic vision of this concept.
\end{abstract}

Keywords: SENAI. Vocational education. Work and training.

\footnotetext{
1 Mestre em Educação, linha de pesquisa História e Historiografia da Educação pela Universidade Federal do Paraná.
} 


\section{Introdução}

Este artigo tem como proposta ver o processo de criação e desenvolvimento do Serviço Nacional de Aprendizagem Industrial (SENAI) do Paraná, destacando a forma como se pensava o ensino dos operários. A filosofia institucional de ensino pautava-se na concepção de Roberto Mange e pode ser percebida em alguns documentos, como relatórios como Histórias e percursos: o departamento nacional do SENAI (1942-2002) de 2002 e De homens e máquinas: Roberto Mange e a Formação Profissional, do Acervo Roberto Mange de 1991. Também exploro reportagens do Jornal O Escudo elaborado pelos próprios alunos do SENAI-PR.

\section{No Contexto da Reforma Capanema}

Desde que assumiu o Ministério em 1934, Gustavo Capanema mostrou seu interesse em desenvolver um amplo programa que aumentasse o número de estabelecimentos destinados a formar mão de obra para a indústria. Naquele mesmo ano, o Ministro Capanema formou uma comissão com este intuito, do qual fazia parte Roberto Mange (do Centro Ferroviário de Ensino e Seleção Profissional); Lourenço Filho (Diretor do Instituto de Estudos Pedagógicos); Leon Reunault (Diretor do Patronato Agrícola João Pinheiro); Joaquim Faria Góes Filho (Superintendente da Educação Secundária e Técnica do Distrito Federal); Horacio da Silveira (Superintendente da Educação Profissional e Doméstica de São Paulo); Artur Torres Filho (Diretor do Serviço de Economia Rural); Lafaiete Belfort Garcia (Diretor da Divisão de Ensino Comercial) e Rodolfo Fuchs (Inspetor do Ensino Industrial) (SÃO PAULO, SENAI, 1991, p. 114).

A comissão teve seis meses de trabalho, de discussões e debates intensos, resultando no Decreto no. 6.029, assinado em 26 de julho de 1940 por Vargas, decreto este que regulamentava a instalação e funcionamento dos cursos profissionais previstos no Decreto no. 1.238 , assinado no ano anterior. 
Segundo Fonseca, a solução não era ainda definitiva, nem as autoridades do ensino ficariam adstritas a elas. As idéias estavam em marcha, buscava-se uma solução que acelerasse o ritmo e incrementasse as atividades do ensino de ofícios (FONSECA, 1986)

Havia uma comissão que trabalhava desde 1936 na elaboração de uma lei que abrangesse todos os aspectos do ensino profissional. Conforme aponta Fonseca, foi em janeiro de 1942, sob o nome de Lei Orgânica do Ensino Industrial, que surgiu a tão esperada legislação que, pouco mais tarde, daria espaço à criação do SENAI - criado com o Decreto-lei no. 4.048, de 22 de janeiro de 1942.

O decreto no. 6.029 de julho de 1940 não seria modificado; ele daria lugar, no entanto, já em 1942, a dois decretos quase simultâneos, um criava o Serviço Nacional de Aprendizagem Industrial, o SENAI, conforme as aspirações da indústria e do ministério do trabalho; e o outro que definia a Lei Orgânica do Ensino Industrial, oriundo das idéias e propósitos da área da Educação. A partir daí, os dois teriam que conviver. $\mathrm{Na}$ fórmula encontrada pelo ministro, o SENAI se encarregaria da "formação profissional dos aprendizes", e seria tão somente uma peça, delegada a Federação Nacional das Indústrias, do amplo painel de ensino profissional estabelecido pela lei orgânica. Todavia, não deixa de ser sintomático que o projeto do SENAI, que só merece oito linhas na longa exposição de motivos de 5 de janeiro de 1942 com a qual Capanema encaminha a Lei Orgânica, termine sendo assinada em primeiro lugar (SCHWARTZMAN, BOMENY; COSTA, 2000, p. 254-255).

Em 1942 era criado o SENAI, sendo esta instituição organizada e mantida pela Confederação Nacional das Indústrias, ofertando diversos cursos de aprendizagem, aperfeiçoamento e especialização, além de possibilitar a reciclagem do profissional.

Depois de verem concretizadas as primeiras medidas governamentais para a regulamentação do SENAI, cabia aos industriais montar o sistema que sustentaria a aprendizagem industrial em todo país, a fim de instalar os diversos Departamentos Regionais - células responsáveis pela implantação do sistema. Também foram criadas regiões administrativas, de acordo com as respectivas atividades industriais. Deste 
modo, em 1942, o SENAI estava organizado, nacionalmente, em dez regiões.

Ao avaliar o desenvolvimento do SENAI nos seus primeiros seis anos de funcionamento, o relatório de 1948, editado pelo Departamento Nacional, em janeiro de 1949, considerava que a história da jovem instituição apresentava três fases distintas (BRASÍLIA, SENAI, 2002):

a) a implantação do Departamento Nacional e dos órgãos locais com prédios alugados;

b)a compra de terrenos, com projeto de prédios definitivos e

c) a atenção ao problema da qualidade de ensino e do rendimento escolar

O SENAI sustentava suas atividades, inicialmente, com a arrecadação de 2 mil réis mensais, por empregado das empresas filiadas à Confederação Nacional da indústria. Quanto ao Departamento Nacional, sua instalação só ocorreu em 3 de agosto de 1942, no Rio de Janeiro, em solenidade presidida pelo Ministro da Educação, Gustavo Capanema (Idem, p. 25).

Importa ressaltar que essa rede de ensino de âmbito empresarial era ambígua. Cunha assinala que esta ambigüidade se dá em uma dimensão pública e privada do SENAI, em decorrência do corporativismo do Estado Novo. Enquanto protagonista do desenvolvimento econômico, empenhado na industrialização, o Estado foi capaz de perceber a necessidade do capital na formação da força de trabalho necessária à sua reprodução ampliada, antes mesmo dos próprios capitalistas. Estes por sua vez, incapazes de tomarem as iniciativas, chegaram a impor resistência aos encargos financeiros que Ihes foram atribuídos (CUNHA, 2000, p. 46).

Mas quem faria a manutenção desta instituição, de onde viriam os recursos financeiros? O Decreto no $4.48 / 42$ estabelecia que a manutenção do SENAI fosse feita pelos estabelecimentos industriais, os quais seriam obrigados ao pagamento de uma contribuição mensal destinada às escolas de aprendizagem, sendo que a arrecadação dessa contribuição deveria ser 
feita pelo Instituto de Aposentadoria e Pensões dos Industriários (IAPI) e repassada ao SENAI.

O ensino industrial assumiu um papel relevante na formação da mão de obra, principalmente no contexto da industrialização do país. Tal foi sua importância que verificamos, a partir de 1942, tanto o Estado como a Confederação Nacional das Indústrias patrocinando esse ensino.

Havia, pois, dois tipos de ensino industrial: um compreendia a aprendizagem sob o controle patronal, ligado ao SENAI; outro, sob a responsabilidade direta do Ministério da Educação e Saúde, constituía-se do ensino industrial básico.

A partir da lei orgânica do ensino industrial, organizou-se o ensino industrial oficial, que ficou dividido em dois ciclos: o primeiro, chamado de fundamental, era ministrado em três ou quatro anos, e havia também o ciclo básico, que compreendia o curso de mestria de dois anos; o segundo ciclo, com duração de três a quatro anos, destinava-se a formação de técnicos industriais. Santos comenta que "era oferecido nesse mesmo ciclo o curso de formação pedagógica, com o intuito de habilitar professores para lecionar no ensino industrial" (SANTOS, 2000, p.271).

O SENAI vem atender as exigências da expansão industrial brasileira, que demandava uma formação mínima do operariado, a qual teria de ser feita de modo eficaz e mais prático. E como assinala Weistein, segundo Raphael Noschese, membro do Conselho Regional do SENAI na década de 1940: "o SENAI aprontava os homens para o mundo, não era para a fábrica do João, do Pedro e do Paulo. A nossa finalidade não é fazer um operário para você, é para São Paulo, para o Brasil" (WEISTEIN, 2000, p. 91).

Porém muitos industriais entendiam o SENAI como uma instituição governamental que estava lá só para tirar o dinheiro deles. Com esta visão, as indústrias enviavam seus aprendizes menos promissores, os "piores alunos", ao SENAI, pois eles consideravam o programa como perda de tempo, mas logo se percebeu que os alunos formados pelo SENAI eram melhores (WEISTEIN, 2000, p, 190). 
Segundo Weinstein, o SENAI era inovador em sua estrutura e em seu caráter ao mesmo tempo público e privado, mas deparava-se com grande ceticismo entre os industriais. Mas mesmo com todo esse "ceticismo" pela parte dos industriais, a imagem do SENAI se fortaleceu, transformando os jovens menos capazes em operários competentes, conquistando assim uma relativa confiança dos industriais.

A equipe do SENAI considerava que os alunos tinham uma educação formal deficiente e baixo padrão de vida e, ainda, destacavam que os alunos tinham padrões morais insuficientes, maus hábitos de trabalho e pouca "cultura".

Weinstein aponta que houve um estudo feito no SENAI para definir o perfil da média de seus aprendizes. O psicólogo responsável por este estudo concluiu que o aluno do SENAI não poderia ser considerado um adolescente comum, porém, ponto de convergência de influências deformativas da personalidade: falta de assistência familiar, trabalho desinteressante, má habitação e alimentação, ambientes inadequados, longo convívio com adultos mal-educados, precocidade de responsabilidades etc. (WEISTEIN, 2000, p. 144) $)^{2}$.

Desta forma, os alunos aprendizes precisavam não apenas ser treinados, mas também levados a aproximar-se da imagem que o SENAI tinha do bom operário. O esforço para produzir um bom operário começava com uma série de testes a que eram submetidos todos os candidatos ao SENAI. A divisão de Seleção e Orientação Profissional usava esses testes não apenas para verificar se o candidato possuía as condições físicas e formação escolar necessárias, mas também para descobrir se as reais aptidões do aprendiz o qualificavam para outro ofício que não fosse o que tivesse escolhido para aprender $e$, se fosse este o caso, encaminhavam o pequeno aprendiz para o curso mais adequado. Weinstein afirma que estes testes tiveram um sucesso relativo, pois os dirigentes do SENAI muitas vezes comentavam a tendência que os alunos tinham de se concentrar nos

\footnotetext{
2 "O Aluno SENAI". Informativo SENAI n. 11(setembro de 1946): O Conceito de comum de d'Avila, psicólogo que fez o estudo não refletia a preponderância numérica, uma vez que os adolescentes da classe operária eram mais numerosos no Brasil que os membros da classe média tomados como referência pelo autor."Normativo seria um termo mais apropriado para o que D 'Avila chama de "comum".
} 
cursos de torneiro mecânico, mesmo quando considerados habilitados para ofícios que ofereciam melhores oportunidades de emprego (WEISTEIN, 2000, p. 144).

Uma vez admitido no programa, o processo de socialização do aprendiz continuava nas oficinas e salas de aulas das escolas do SENAI. A instituição sempre apresentava sua instrução prática como puramente técnica, e todo o seu programa como ideologicamente neutro, mas Roberto Mange defendia o método de Formação Seqüencial como um meio de incutir disciplina e eficiência nos operários aprendizes.

O SENAI acreditava em uma educação moral cívica, mas também considerava a oficina como um lugar de socialização, com ênfase na ordem, autocontrole e hierarquia. Para Weinstein,

a própria concepção do SENAI refletia o conceito de Mange de uma hierarquia industrial composta rigidamente, em ordem ascendente, por trabalhadores não-especializados (braço anatômico), trabalhadores semi-especializados (braço atento), operários especializados (braço pensante), e encarregados da supervisão (braço pensante e dirigente). Nas palavras de Evaldo Lodi, pronunciadas na inauguração da Escola Roberto Simonsen do SENAI: 'Nas escolas industriais do SENAI, a ordem primorosa, a pontualidade exata, a limpeza irrepreensível, a obediência constante, o sentido de hierarquia constituem lições vivas que embebem todos os jovens' (WEISTEIN, 2000, p. 145).

No Paraná, no SENAI de Curitiba, um aluno assim descrevia a sua escola no início da década de 1950:

O SENAI é uma escola a qual os alunos devem muito do seu aperfeiçoamento. é nela que entram os que desconhecem uma profissão, saindo, após a aprendizagem, oficiais. Aqui, nesta grande escola, só não aprende quem não quer. Ha muitos que não a merecem e, no entanto aqui estão no lugar de muitos que seriam melhores. É por meio dos mestre, que Curitiba, o Paraná, o Brasil, cada vez mais vão possuindo mecânicos, marceneiros, eletricistas, soldadores, afiadores, gráficos, pedreiros - gente especializada, homens úteis em todos os ramos. Estudemos com arrojo e coragem não só nas oficinas, mas na teoria também Salve o SENAI, uma das melhores 
escolas do Paraná. Ademar Cunha - 40 CAO (O ESCUDO, out. 1950)

Era esta a imagem ideal desenvolvida por Roberto Mange e partilhada por seus colaboradores, a de uma instituição de formação orientada para operários de menor idade que teriam uma instrução teórica alternada com a experiência prática em seu local de trabalho. Roberto Mange trouxe para o SENAI sua longa experiência como diretor do IDORT e como professor de engenharia mecânica na escola politécnica, e sua enorme bagagem intelectual, com teorias sobre métodos adequados para a formação e socialização dos industriários aprendizes.

Como é figura importante no processo de implementação do SENAI, aqui retomamos a biografia de Roberto Mange. Nasceu em Vevey, na Suíça, a 31 de dezembro de 1886, tendo obtido o diploma de estudos primários em Portugal, secundários na Alemanha e de engenheiro pela Escola Politécnica de Zurich, em 1910. Em 1913, com 28 anos, veio para o Brasil, pelas mãos de Paula Souza, contratado para a cadeira de Mecânica Aplicada as máquinas, na Politécnica de São Paulo, onde lecionou pelo espaço de 40 anos, cargo em que se aposentou, sendo declarado Professor Emérito em 1953. Em 1923, fundou junto ao Liceu de Artes e Ofícios de São Paulo, a Escola Profissional Mecânica, onde elaborou, com um grupo de estudiosos, as conhecidas séries metódicas de ofícios. Em 1929, partiu para a Europa, tendo ocasião de estudar na Alemanha a aprendizagem de operários nas estradas de ferro daquele país. Dois anos depois, com Armando Salles Oliveira, Gaspar Ricardo, Geraldo de Paula e Souza, Aldo Mario de Azevedo, Lourenço Filho e outros, fundou o Instituto de Organização Racional do Trabalho (IDORT), destinado a: aumentar o bem estar social por meio de uma organização adequada a cada setor do trabalho e cada atividade; estudar, difundir e aplicar os princípios, métodos, regras e processos da organização científica do trabalho; evitar o desperdício sob suas múltiplas modalidades; dar o máximo de rendimento com o mínimo de toda segurança; quer sob o ponto de vista de atingir de forma plena a sua finalidade, quer sob o aspecto de eficiência qualitativa e quantitativa de operações. Assegurar administrações cientificamente exercidas. De 1940 a 
1942, cuidou ele, em colaboração de outros expoentes da indústria, da fundação do SENAI, do qual foi o primeiro Diretor Regional em São Paulo, exercendo o cargo até sua morte em 1955. Segundo Bologna, com a concepção humanista que teve, especialmente quando diretor do SENAI, dos múltiplos interesses e necessidades do aluno-aprendiz, o que fez brotar de "sua generosidade e bondade", inúmeras obras de assistência e de acompanhamento desse jovem, concretizadas em serviços médicos, dentários, alimentares, esportivos, recreativos e culturais (BOLOGNA, 1980, p. 14).

A organização, a disciplina se refletia em todas as escolas do SENAI, marcando claramente o tipo de cultura institucional que o aluno-aprendiz deveria aceitar e internalizar.

A organização do SENAI difere profundamente da rede de escolas Industriais, pois se destina a aprendizes que já pertencem à indústria e que ganham salários, mesmo nos dias em que freqüentam as Escolas de Aprendizagem do SENAI, ao passo que os alunos das escolas Industriais são exclusivamente alunos e freqüentam a escola a custa própria (BOLOGNA, 1980, p. 02).

Contudo o SENAI-SP em seus primeiros anos encontrou algumas dificuldades de ordem estrutural e pedagógica:

\begin{abstract}
Durante os seis primeiros meses de 1942 a recém-formada administração do SENAI/SP vasculhou a capital e o interior em busca de instrutores, instalações adequadas para cursos, e potenciais estudantes. Oferecendo salários $20 \%$ acima dos que eram pagos pelas escolas públicas, o SENAI teve pouca dificuldade em atrair uma equipe docente para matérias convencionais como português e matemática. O recrutamento de instrutores para tarefas práticas, que deveriam fazer um exame de qualificação e ter pelo menos cinco anos de experiência na indústria com $o$ respectivo tipo de especialização, revelou-se mais difícil (WEISTEIN, 2000, p. 137).
\end{abstract}

As escolas do SENAI, quando comparadas com as de ensino industrial das redes públicas, evidenciavam de modo patente a inferioridade destas. A autonomia que lhes faltava, a adesão de alunos motivados (e remunerados), a possibilidade de organizar cursos conforme as demandas 
locais, o entrosamento com empresário-consumidores da força de trabalho qualificada eram qualidades do SENAI cuja carência, nas escolas industriais, mostrava necessidade urgente de modificar os cursos básicos, senão acabar com eles (CUNHA, 2000, p. 48).

Houve ainda uma complementação da regulamentação do SENAI que contribuiu para o sucesso de seus cursos, o Decreto no 4.481 de 16 de julho de 1942, obrigava as empresas do ramo industrial a custear os cursos e manter em seus quadros $8 \%$ de menores aprendizes do total de operários. A prioridade era dada aos filhos de operários empregados nos estabelecimentos industriais; aos irmãos dos operários que atuavam nas indústrias e aos órfãos cujos pais estivessem vinculados ao ramo industrial.

No jornal dos alunos da escola do SENAI de Curitiba, aborda-se a importância da legalização do trabalho do menor operário,

\begin{abstract}
De acordo com a lei, todo menor que trabalha deve possuir carteira profissional. Assim sendo logo que matriculamos e empregamos um aluno no SENAI, imediatamente providenciamos a mesma. Entregamos ao menor uma relação de documentos necessários e os respectivos impressos: declaração de função, a ser preenchido pela firma e autorização de responsável, para ser assinado pelo responsável pelo menor. Depois de reunidos todos os documentos solicitados, a escola oferece uma "declaração" de que o aluno sabe ler e escrever. Juntamos esta aos demais documentos e levemos tudo a Delegacia Regional do Trabalho. Dois ou três dias depois o aluno vai à referida delegacia e recebe a sua Carteira Profissional de Menor. Dessa maneira, com satisfação, a escola vê todos seus alunos munidos de importante documento (O ESCUDO, Nov. 1952).
\end{abstract}

A nota sobre a questão da legalidade do trabalho do menor operário constante em "O Escudo" revela á comunidade de operários que, além da instituição prover uma vaga de emprego para o pequeno aprendiz, o faz dentro da legalidade, propiciando segurança e reconhecimento ao aluno aprendiz. Percebe-se que, com os cursos profissionalizantes do SENAI, incluindo-se também a trajetória da educação profissional no Brasil, teve-se uma preocupação com os "desfavorecidos da fortuna", exercendo-se sempre um papel social extraordinário em função da própria legislação educacional. 
Ao estabelecer a idade mínima de catorze anos para ingresso no emprego, a legislação acabou gerando aquilo que no SENAI ficou conhecido como hiato nocivo, já que, para a população pobre, a escolarização raramente ultrapassava o ensino primário, quase sempre concluído em idade superior a dez anos. Por isso, o SENAI foi obrigado a sentir o problema bem de perto, pelo fato de receber muitos jovens após um período mais ou menos longo de interrupção da escola primária, gasto em vadiagem ou em pequenos misteres. Intentando solucionar o problema, o SENAI criou os cursos vocacionais, onde valorizava, sobretudo, o trabalho manual e onde se buscavam mecanismos que pudessem preencher o chamado hiato nocivo (BRASÍLIA, SENAI, 2002, p. 25)

Weinstein assinala que a educação de crianças com idades entre doze e quatorze anos era uma área de especial interesse do SENAI, nos cursos chamados vocacionais (WEINSTEIN, 2000, p. 150). Desde o debate sobre a lei do trabalho infantil na década de 1920, os industriais e engenheiros sociais de vários matizes vinham denunciando o "hiato nocivo", ou melhor, o intervalo entre os doze anos, quando normalmente a criança acaba o curso primário, e os catorze anos, quando a lei autorizava sua entrada no mercado de trabalho. Embora alguns patrões soubessem que essas crianças provavelmente preenchiam este hiato nocivo com um emprego ilegal ou com trabalhos no setor informal, os educadores temiam que aqueles dois anos de atividade sem acompanhamento e sem regularidade levassem a comportamentos nocivos e mesmo criminosos e tornasse mais difícil para os aprendizes, a adaptação na rotina da fábrica.

O jornal "O Escudo" em 1949, fazia chamadas a procura de aprendizes em idade do "hiato nocivo", em tom de convocação para o progresso e prosperidade da nação. Mesmo que sua circulação fosse interna, ainda assim atingia os aprendizes que já se encontravam na instituição e que poderiam trazer irmãos, parentes, amigos.

Mange afirma "que é justamente durante esse tempo que o menino adquire vícios e sofre, pela ausência da escola, acentuado retrocesso intelectual e moral", ele ainda lamenta que "centenas e centenas de crianças se entreguem a perigosa ociosidade das ruas" (WEINSTEIN, 2000, p. 150)

A solução para tal situação, sob o ponto de vista do SENAI, foi ofertar cursos vocacionais à parte para crianças com idade abaixo do 
mínimo exigido para aprendizes do SENAI. O currículo elaborado para esses menores tinha dois objetivos básicos: aperfeiçoar sua cultura geral e iniciálos em várias ocupações manuais.

O SENAI não procurava preparar esses alunos para um determinado ofício, mas sim colocá-los em contato com várias ocupações manuais,

Mange ressalta,

O caráter do SENAI pode levar alguém à apressada e falsa conclusão de que se trata de mera organização de ensino profissional, o que não é verdade. Cumpre não perder de vista o verdadeiro sentido da obra que compete ao SENAI promover, ou seja, o conceito educativo-social de suas realizações. Esta orientação implica necessariamente dentro do âmbito de aprendizagem industrial na realização de serviços de natureza para-escolar no campo da educação, da higiene e da assistência social. Serviços esses que embora representem, evidentemente, um forte acréscimo no custo de cada aluno, constituem, todavia, condição precípua para a eficiência do ensino (MANGE apud BOLOGNA, 1980, p. 378).

Este discurso proferido por Mange afirma a cultura institucional que se pretendeu incorporar ao SENAI desde a sua fundação, em que a disciplina, a ordem, a higiene seriam mecanismos para se alcançar um alto conceito educativo social dentre os aprendizes.

Roberto Mange apontará sobre tudo a compatibilidade entre formação técnica e a denominada "educação integral do individuo". Para ele a técnica tinha caráter utilitário, devido ao rigor da racionalidade e da rapidez destoando do conceito espiritualista da "educação integral". Nesta perspectiva os aprendizes eram educados, passado período dos cursos vocacionais.

Dessa maneira, o problema de aprendizagem dos industriários não se limitava ao aspecto pedagógico, relacionado ao trabalho, mas tinha preocupações com a valorização total do operário, isto é, com a "Educação integral" tão almejada por Mange, que pode ser definida como "cultura geral e profissional em torno de uma sadia personalidade" (Idem, p. 215).

Salienta Bologna, 
Seria inútil que o SENAI cuidasse unicamente do ensino, pois ele não se propõe apenas a ensinar, mas principalmente a educar. Por isso mesmo, a missão do SENAI não pode ser exclusivamente de natureza técnica. Não se trata simplesmente do problema da formação profissional do trabalhador, mas de uma ação educativa de sentido muito mais amplo e elevado, visando acima de tudo formar o cidadão, isto é, fazer do aprendiz um homem integro, moral física e profissionalmente falando, cioso das prerrogativas inerentes a sua dignidade de pessoa humana e consciente de sua responsabilidade pessoal e profissional com a coletividade (Idem, p. 215).

As aspirações de Mange, segundo o relatório do SENAI-SP de 1946, implicavam o desenvolvimento da cultura geral, da educação moral e cívica e das lides abrangidas pelo Serviço Social, para procurar elevar o espírito do aprendiz. Para Mange subsiste algo de antagônico com a rigidez da técnica do trabalho em que a individualidade, o culto pela matéria, o senso artístico e o amor ao belo não tem oportunidade de se expandir. Com estas palavras, o idealizador do SENAI expõe contundente crítica ao trabalho que estava sendo desenvolvido pelo SENAI, deixando claro que suas reflexões pela educação integral dentro do contexto da aprendizagem industrial deveriam tornar-se mais presentes nas escolas. Segundo Bologna, os fundamentos da orientação do ensino decorrem do aspecto psico-social e profissional do aprendiz-aluno, o que requer uma perfeita adaptação a essa mentalidade especial do adolescente, sujeita as mais variadas influências no setor do trabalho, da sociedade e do lar.

Buscando seus objetivos, Mange alterou várias posturas que até então pareciam indestrutíveis. Uma delas era sobre o tipo de escolas construídas; outra dizia respeito aos métodos de ensino adotados pelo SENAI. Havia necessidade de utilizar a psicologia do aluno, eliminando a rigidez curricular tradicional, o que se traduz em uma inversão da linha de ação pedagógica. Segundo ele não era o professor que deveria inculcar a matéria ao aluno, mas sim o aluno que deveria desejar adquirir os conhecimentos, o como e o porquê da prática e da teoria do seu ofício (SÃO PAULO, SENAI, 1991, p. 140).

O aprendiz já ocupado com a atividade industrial e que é aluno dos cursos do SENAI, apresentava características bem diferentes de um menor 
que freqüenta o curso primário, secundário ou uma escola industrial, pois é um aprendiz que produz na fábrica, ganha seu salário e possui acentuada independência. E no âmbito social e familiar em que vive pouco estímulo encontraria para melhorar sua cultura geral e elevar seu conceito cívico e moral. Mange também destaca a aprendizagem do SENAI com foco no perfil do aprendiz:

\begin{abstract}
Atentemos, por exemplo, para o caso do aprendiz de nossas escolas: se bem que menor, ele não deixa de ser um pequeno operário relativamente independente, que se comporta dentro da fábrica como homem que produz e ganha seu salário. Por isso mesmo, o aluno das Escolas SENAI é completamente diferente daquele que freqüenta as demais escolas industriais e secundárias. Tanto se saliente a personalidade definida do aprendiz na fábrica, como na família a qual presta sua ajuda [...]. Este tríplice aspecto do aluno, operário e membro de certa sociedade, deve ser cuidadosamente considerado para que se tenha uma idéia real do tipo de aluno que freqüenta as Escolas SENAI (Idem, p.137).
\end{abstract}

Como se pode observar na cultura institucional do SENAI, foi muito demarcado o comportamento do aprendiz como parte do ensinoaprendizagem e de sua formação. Para Bologna:

Os métodos de ensino adotados pelo SENAI visam, de modo geral, a educação eficiente do aprendiz. Para isso, são utilizados todos os processos pedagógicos recomendáveis, procurando-se tornar a Escola ativa e interessante. De acordo com cada disciplina, são empregados processos de ensino que levam o aluno a pensar por si os problemas de sua vida real (BOLOGNA, 1980, p.214).

Tendo como meta possibilitar uma educação profissional de qualidade e também humanista, o SENAI propôs o método de instrução individual, que compreendia quatro fases: estudo do assunto; comprovação do conhecimento; aplicação, generalização ou transferência do conhecimento; e, avaliação.

Cunha elucida que, no início da existência do SENAI, não se tinha a necessidade de dissimular a diretividade de seu método de ensino, nem a padronização de procedimentos (CUNHA, 2000, p. 69). Tanto uma como outra eram vistas como tendo vantagens óbvias. A razão pela qual essa 
metodologia de caráter taylorista foi revestida pelo ativismo parece ser a necessidade de responder as críticas vindas de dentro e de fora da instituição - de dentro, em razão das mudanças dos processos produtivos, cada vez mais difíceis de serem acompanhados devido às adaptações das folhas de operações e de tarefas; de fora, pela prevalência do não diretivismo no campo pedagógico, com motivação tanto de caráter psicológico quanto de caráter social e político.

\section{Considerações Finais}

A concepção de ensino defendida pelo SENAI e por Roberto Mange inicialmente era a organização racional do trabalho, sistematizada por Frederick Taylor. O taylorismo visava à organização administrativa, a utilização adequada de matérias primas, da força de trabalho e da energia motriz, e também defendia a implantação de um controle eficiente de custos, foi essa redução permitiria a elevação da produtividade. Roberto Mange foi o difusor destas idéias aplicadas dentro do SENAI, e também fundador ao lado de Lourenço Filho e outros, do IDORT, Instituto de Organização Racional do Trabalho, que pretendia aumentar o bem estar social por meio de uma organização racional.

O conteúdo ideológico e pedagógico do curso do SENAI propiciava ao aprendiz um sentimento de autoestima, de confiança e de auto-realização, resultado de eficácia do ensino ministrado e da sintonia com o ambiente da empresa. Esta era a perspectiva alimentada pela instituição, perspectiva aparente nos artigos elaborados pelos aprendizes no jornal da associação dos alunos do SENAI-PR.

Nota-se que a organização e a disciplina marcam a concepção de ensino difundida pela instituição, o que Mange chamava de ordem educativa e social, cujo objetivo maior centrava-se na educação integral conjugado com uma formação técnica e social. 


\section{Referências}

BOLOGNA, I. Roberto Mange e sua obra. [S.I.]: Unigraf, 1980.

CUNHA, L. A. O ensino industrial-manufatureiro no Brasil. Revista Brasileira de Educação. ANPED, n.14, maio./ago. 2000, p. 89-107.

FONSECA, C. S. História do ensino industrial no Brasil. Rio de Janeiro: SENAI/DPEA, 1986.

SANTOS, J. A. dos. A trajetória da educação profissional. In VEIGA, C. G. et al (Org.). 500 Anos de Educação no Brasil. Belo Horizonte: Autêntica, 2000.

SCHWARTZMAN, S.; BOMENY, H. M. B.; COSTA, V. M. R. Tempos de Capanema. São Paulo: Paz e Terra, 2000.

WEISTEIN, B. (Re) formação da classe trabalhadora no Brasil (1920-1964). São Paulo: Cortez, 2000.

\section{Fontes Históricas}

BRASÍLIA, SENAI. Relatório. Histórias e percursos: o departamento nacional do SENAI (1942-2002), 2002.

O ESCUDO - Órgão oficial dos alunos do SENAI. Curitiba: Oficina de Artes Gráficas da Escola do SENAI, 1949-1962.

SÃO PAULO, SENAI, Relatório. De homens e máquinas: Roberto Mange e a Formação Profissional. Acervo Roberto Mange: Inventario Analítico, v.1, 1991. 